\title{
Transcriptional analysis of the lichenase-like gene cel12A of the filamentous fungus Stachybotrys atra BP-A and its relevance for lignocellulose depolymerization
}

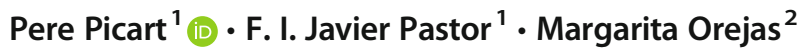 \\ Received: 31 July 2020 / Revised: 3 November 2020 / Accepted: 14 December 2020 / Published online: 6 January 2021 \\ (C) Springer Nature Switzerland AG 2021
}

\begin{abstract}
To rationally optimize the production of industrial enzymes by molecular means requires previous knowledge of the regulatory circuits controlling the expression of the corresponding genes. The genus Stachybotrys is an outstanding producer of cellulosedegrading enzymes. Previous studies isolated and characterized the lichenase-like/non-typical cellulase Cel12A of S. atra (AKA S. chartarum) belonging to glycosyl hydrolase family 12 (GH12). In this study, we used RT-qPCR to determine the pattern of expression of cel12A under different carbon sources and initial ambient $\mathrm{pH}$. Among the carbon sources examined, rice straw triggered a greater increase in the expression of cel12A than $1 \%$ lactose or $0.1 \%$ glucose, indicating specific induction by rice straw. In contrast, cel12A was repressed in the presence of glucose even when combined with this inducer. The proximity of 2 adjacent 5'-CTGGGGTCTGGGG-3' CreA consensus target sites to the translational start site of cell $2 \mathrm{~A}$ strongly suggests that the carbon catabolite repression observed is directly mediated by $\mathrm{CreA}$. Ambient $\mathrm{pH}$ did not have a significant effect on cell $2 \mathrm{~A}$ expression. These findings present new knowledge on transcriptional regulatory networks in Stachybotrys associated with cellulose/hemicellulose depolymerization. Rational engineering of CreA to remove CCR could constitute a novel strategy for improving the production of Cel12A.
\end{abstract}

Keywords Stachybotrys $\cdot$ Lichenase $\cdot$ Transcription regulation $\cdot$ RT-qPCR $\cdot$ Agricultural waste $\cdot$ Biomass depolymerization

\section{Introduction}

Filamentous fungi have the ability to produce a plethora of extracellular enzymes enabling them to utilize a wide spectrum of plant cell wall polysaccharides (e.g., cellulose, hemicelluloses, and pectins), and thus they play a key step in the carbon cycle. The ecological and biotechnological importance of fungi and their extracellular plant cell wall-degrading enzymes (PCWDEs), as well as the importance of these enzymes in fungal nutrition and lifestyles, have promoted interest

F. I. Javier Pastor fpastor@ub.es

$\triangle$ Margarita Orejas morejas@iata.csic.es

1 Department of Microbiology, Faculty of Biology, University of Barcelona, Avinguda Diagonal 643, 08028 Barcelona, Spain

2 Instituto de Agroquímica y Tecnología de Alimentos, Consejo Superior de Investigaciones Científicas (IATA-CSIC), Avda. Agustín Escardino 7, 46980 Paterna, Valencia, Spain towards understanding the molecular mechanisms controlling their production. As the production of extracellular enzymes in large quantities is an energy-consuming process, it is not surprising that the enzymatic degradation of plant polysaccharides and the subsequent utilization of their components as carbon and energy sources are highly regulated events (at the level of transcription) that ensure the hierarchical and conditional use of these substrates (MacCabe et al. 2002; Aro et al. 2005).

Carbon source-dependent regulation of genes encoding PCWDEs occurs by at least two independent mechanisms: induction in the presence of the polymeric substrate or its degradation products and carbon catabolite repression (CCR) triggered by easily metabolizable carbon sources such as glucose (Martin et al. 2007; Amore et al. 2013; Adnan et al. 2018). Since plant polysaccharides are too large to enter the fungal cell, it is commonly accepted that their capacity to induce the expression of PCWDE genes resides in the production of a basal level of extracellular enzymatic activity that results in the liberation of a soluble inducer (reviewed by Amore et al. 2013). PCWDE gene induction has been studied 
in a number of filamentous fungi. In Hypocrea jecorina (Trichoderma reesei), Neurospora crassa, Aspergillus niger, and Aspergillus nidulans, the binuclear zinc cluster (Zn2Cys6) transcription factors CLR-1/ClrA (proposed binding site $5^{\prime}-\mathrm{CGGN}_{5} \mathrm{CGGNCCG}^{-3}$ '), CLR-2/ClrB (5'$\mathrm{CGGN}_{11} \mathrm{CGG}^{\prime} 3^{\prime}$ or $5^{\prime}$-YAGAAT-3'), Ace $2 /$ AceB (5'-GGCT AATAA-3' or $5^{\prime}$-GGGTAAATTGG-3' or $5^{\prime}-\mathrm{GGCW}_{4} \mathbf{3}^{\prime}$ ), and XlnR/Xyr1/Xlr-1 (5'-GGCTAA-3', 5'-GGCTRRR-3', 5'GGCWWW-3') activate the expression of genes required for cellulose and/or hemicellulose deconstruction (see Coradetti et al. 2012; Amore et al. 2013; Huberman et al. 2016; Benocci et al. 2017; and references therein), though not all these factors are ubiquitous in these organisms (and others) and the gene sets activated are not necessarily identical.

CCR is a general regulatory mechanism that also controls whether PCWDEs are produced or not. In the presence of preferred carbon sources such as glucose, the expression of genes required for the utilization of alternative carbon sources (e.g., cellulose, hemicellulose) is prevented by the widedomain Cys2His2-type zinc finger repressor CreA/CRE1/ CRE-1 (see Amore et al. 2013; Huberman et al. 2016; Benocci et al. 2017; and references therein). CreA has been extensively characterized in A. nidulans, and CreA homologs have been also found in other filamentous fungi. It has been shown that CCR is exercised via binding of CreA to DNA targets with the consensus sequence 5'-SYGGRG-3' (Kulmburg et al. 1993; Cubero and Scazzocchio 1994).

In addition, though not being carbon source regulation, the enzymatic breakdown of plant cell wall polymers can occur at different environmental $\mathrm{pH}$ values, and fungi have also developed regulatory circuits to ensure that the metabolically costly synthesis of PCWDEs does not occur under unfavorable $\mathrm{pH}$ conditions where these enzymes are less active. The regulatory mechanism controlling $\mathrm{pH}$-dependent transcriptional regulation has been extensively analyzed in A. nidulans, and a major role for the Cys2His2 wide-domain $\mathrm{pH}$ regulator PacC (binding site 5'-GCCARG-3') has been shown (see Peñalva and Arst Jr 2004; Peñalva et al. 2008; and references therein). The first demonstration that the expression of fungal genes encoding extracellular PCWDEs is regulated by environmental $\mathrm{pH}$ via $\mathrm{PacC}$ was that of the xylanolytic genes $x \ln A$ and $x \ln B$ of $A$. nidulans (MacCabe et al. 1998).

The genus Stachybotrys (Sordariomycete class) comprises several species, most having been isolated from agricultural wastes and other decomposing cellulosic materials (AbdelMallek 1994; Wang et al. 2015). These biomass-degrading fungi thus exhibit efficient enzymatic systems for the degradation of these substrates, including alkaline-resistant and thermostable cellulases, and $\beta$-glucanases with potential applications in the paper, textile, food, and biofuel industries (Picart et al. 2016; Picart et al. 2008; Saibi et al. 2007; Taylor et al. 2002; Tweddell et al. 1996). Notwithstanding the biotechnological relevance of Stachybotrys, studies on transcriptional regulatory networks controlling the expression of its PCWDE genes are scarce at present. Only a few studies reporting the expression of $\beta$-glucosidase genes of Stachybotrys microspora (using semi-quantitative RT-PCR assays) have been reported (Abdeljalil et al. 2013, 2014; Ben Hmad et al. 2014). In addition, few studies on the expression of genes involved in the mycoparasitism of Stachybotrys elegans have been also published (Morissette et al. 2003, 2006, 2008; Chamoun et al. 2015). Probably, the fact that several strains of the genus Stachybotrys have been reported as potentially toxigenic has hampered the study of their biomass-degrading enzymatic system (Etzel et al. 1998; Brasel et al. 2005).

We have previously isolated the strain S. atra BP-A from a rotting cellulose rag, and one of the genes encoding a major PCWDE produced by this strain (cel12A) has been cloned and characterized (Picart et al. 2012). The product of this gene, Cel12A, belongs to the glycosyl hydrolase family 12 (GH12) and was found to be a lichenase-like or non-typical cellulase showing low activity on cellulose but high activity on lichenan ( $\beta$-1,3-1,4-glucan) and barley mixed glucans $((1 \rightarrow$ $3,1 \rightarrow 4)-\beta$-D-glucans). These properties show the potential application of Cel12A in the brewing and wine industries to facilitate filtration processes; in animal foodstuffs to improve $\beta$-glucans digestibility and nutritive quality; to produce valuable oligosaccharides; and in the processing of agricultural and industrial wastes for producing bioethanol and biodiesel (Thomas 1956; Goldenkova-Pavlova et al. 2018; Chaari and Ellouz Chaabouni 2019). The aim of the present work was to study (real-time RT-qPCR) the effect of different carbon sources and initial $\mathrm{pH}$ values on the expression of cel12A. To the best of our knowledge, this is the first report on the regulation of a lichenase gene in the genus Stachybotrys and established a possible direct role for the carbon catabolite repressor CreA and its CCR. We have identified (orthology predictions) putative transcription regulators of the PCWDE gene cel12A in the genus Stachybotrys. We believe that this work could be relevant to study the regulation of other PCWDE genes (e.g., encoding thermostable cellulases), as well as genes associated with mycoparasitism (e.g., sechi44 encoding a chitinase repressed by glucose; Morisette el al., 2006) in the genus Stachybotrys, an outstanding cellulolytic fungus.

\section{Material and methods}

\section{Strains and culture conditions}

Stachybotrys atra BP-A was previously isolated in our research group and maintained at $30^{\circ} \mathrm{C}$ on potato dextrose agar (PDA) as described (Picart et al. 2008). Rice straw was 
collected from Oryza sativa cultivated fields in La Albufera de Valencia (Spain).

To obtain mycelium for enzyme production and RNA extraction under different growth conditions, $10^{6}$ spores $/ \mathrm{mL}$ were inoculated in $50 \mathrm{~mL}$ of non-buffered basal media (BM; pH 6.5) (Mandels and Weber 1969) supplemented with $1 \%$ $(\mathrm{w} / \mathrm{v})$ glucose and incubated at $30^{\circ} \mathrm{C}$ and $200 \mathrm{rpm}$. After $24 \mathrm{~h}$, pregrown mycelium was filtered, washed, and transferred to fresh $50 \mathrm{~mL}$ BM, supplemented with the following carbon sources: $1 \%(\mathrm{w} / \mathrm{v})$ glucose, $0.1 \%(\mathrm{w} / \mathrm{v})$ glucose, $1 \%(\mathrm{w} / \mathrm{v})$ lactose, $1 \%(\mathrm{w} / \mathrm{v})$ rice straw, $1 \%(\mathrm{w} / \mathrm{v})$ rice straw $+1 \%$ $(\mathrm{w} / \mathrm{v})$ glucose, and $1 \%(\mathrm{w} / \mathrm{v})$ rice straw $+0.1 \%(\mathrm{w} / \mathrm{v})$ glucose, and incubated for another $16 \mathrm{~h}$ at $30{ }^{\circ} \mathrm{C}$ and $200 \mathrm{rpm}$. Similarly, to achieve the different conditions with respect to ambient $\mathrm{pH}$, pregrown mycelium $(\mathrm{BM}+1 \%$ glucose) was transferred to induction media $(\mathrm{BM}+1 \%$ rice straw) buffered to acidic ( $\mathrm{pH}$ 5.2) or alkaline $(\mathrm{pH}$ 7.9) conditions using $100 \mathrm{mM}$ phosphate and $200 \mathrm{mM} \mathrm{Na}^{+}$as described (Orejas et al. 1995) and incubated for another $16 \mathrm{~h}$ at $30{ }^{\circ} \mathrm{C}$ and $200 \mathrm{rpm}$. After incubation, supernatants were collected for lichenase activity assay and protein quantification, whereas the mycelia were harvested by filtration using Miracloth filters (Calbiochem®, CA, USA) for subsequent RNA extraction. All experiments were done by triplicate.

\section{Lichenase activity assay and protein quantification}

Enzyme activity was assayed by measuring the amount of reducing sugars released from lichenan using the method of Nelson and Somogyi (Spiro 1966). The assay mixtures contained $1.5 \%(\mathrm{w} / \mathrm{v})$ lichenan in a final volume of $0.1 \mathrm{~mL}$ of $50 \mathrm{mM}$ phosphate buffer at $\mathrm{pH}$. The mixtures were incubated at $45{ }^{\circ} \mathrm{C}$ for $15 \mathrm{~min}$. Color development was measured at $520 \mathrm{~nm}$. One unit of lichenase activity was defined as the amount of enzyme that released $1 \mu \mathrm{mol}$ of reducing sugar equivalent per min under the assay conditions described.

The Bradford protein assay was used to measure the concentration of total extracellular proteins (Bradford 1976) using BSA as standard. All assays were performed in triplicate.

\section{RNA extraction and reverse transcription}

Harvested mycelia were immediately ground in liquid nitrogen to a fine powder. Total RNAs were extracted by using the FastRNA ${ }^{\circledR}$ kit (Qbiogene) and treated with RNase-free DNase ITM (QIAGEN) according to the manufacturer's recommendations. The RNA concentration and purity (A260/A280 and 260/230 ratios) were determined using a Nano-Drop ND-1000 spectrophotometer (NanoDrop Technologies), and agarose $(1.1 \% \mathrm{w} / \mathrm{v})$ gel electrophoresis was conducted to visualize the integrity of the RNAs. Only undegraded RNA samples with an A260/A280 ratio between
1.9 and 2.1 and A260/A230 ratios greater than 2.0 were used for the analyses.

First strand cDNAs were synthesized from $1 \mu \mathrm{g}$ of total RNA using random hexamers as primers and SuperScript ${ }^{\mathrm{TM}}$ II (MoMLV-RT, Roche) according to the manufacturer's instructions.

\section{Expression analysis of cel12A by real-time quantita- tive RT-qPCR}

RT-qPCR was performed for the target gene cel12A and for the housekeeping reference gene $18 S$ rRNA using the GeneAmp 5700 Sequence Detection System (PE Applied Biosystems) and the TaqMan ${ }^{\circledR}$ probe (Applied Biosystems), following the manufacturer's instructions. Amplification assays were performed in $30 \mu \mathrm{L}$ reactions containing the following concentrations: 0.9 mmols of each primer, $0.2 \mathrm{mmols}$ TaqMan ${ }^{\circledR}$ probe, 1 unit of HotSplit DNA polymerase (Biotools), and $10 \mathrm{ng}$ of template cDNA. Primers and TaqMan ${ }^{\circledR}$ probes used are listed in Table 1. The amplification conditions were $95^{\circ} \mathrm{C}$ for $10 \mathrm{~min}$ (hot start), followed by 40 cycles at $95^{\circ} \mathrm{C}$ for $15 \mathrm{~s}$ and $1 \mathrm{~min}$ at $60^{\circ} \mathrm{C}$. Reactions without cDNA functioned as negative controls. All assays were performed in triplicate. Following amplification, the specificity of the PCR products was confirmed by melting curve analyses.

We choose to use RT-qPCR instead northern blotting because it is more convenient for the detection and quantification of relative amounts of mRNA (i.e., it does not require large amounts of RNA), highly sensitive, accurate, and reproducible, thus allowing the examination of cell $2 \mathrm{~A}$ expression under different conditions including those resulting in very low levels of expression.

\section{Data quantification}

Relative cel12A expression analysis was performed by the $2^{-\Delta \Delta \mathrm{Ct}}$ method (Morse et al. 2005) and normalized against the expression of $18 S r R N A$, which exhibited no significant $\mathrm{C}_{\mathrm{t}}$ (threshold cycle) variation in all tested experimental conditions. Real-time RT-qPCR data were calculated as relative expression values (fold change) of cell $2 \mathrm{~A}$ in the analyzed conditions. The expression level of cel12A in non-buffered BM media supplemented with $1 \%$ rice straw as a sole carbon source was arbitrarily assigned as the reference sample with a $2^{-\Delta \Delta \mathrm{Ct}}$ value of 1.0 .

\section{In silico analysis of putative transcription factors (TF) and TF binding sites in the promoter of cel12A}

The recent availability of the genome sequence of S. chartarum IBT 40288 (https://fungi.ensembl.org/ Stachybotrys_chartarum_ibt_40288_gca_000732765/Info/ Index) was used to obtain the 5 '-upstream region (800 bp) of 
Table 1 Primers used in this study

\begin{tabular}{lll}
\hline Name of the primer & Sequence $\left(5^{\prime}-3^{\prime}\right)$ & Expected size $(\mathrm{pb})$ \\
\hline Cel12a_Fwd & TCGTTTCTTGGATTGGGT & 116 \\
Cel12a_rev & GGTAGAGTGATTAGGGTT & 116 \\
Cel12a_taqman & CGGATGTTGTTGCCCTGGT & TaqMan probe \\
rRNA18S_Fwd & TGACTCAACACGGGGAAA & 116 \\
rRNA18S_rev & CACCCCACCAACTAAGAA & 116 \\
rRNA18S_taqman & ATGCACCACCACCCACAAA & TaqMan probe \\
\hline
\end{tabular}

cel12A and also to search (BLASTP; Altschul et al. 1997) for potential homologs to known fungal transcription factors that could be involved in the regulation of cell $2 \mathrm{~A}$.

\section{Results and discussion}

\section{Gene structure of cel12A and promoter analysis}

The cel12A gene of $S$. atra BP-A (GenBank accession no. AM180511) contains an 848 bp open reading frame (ORF) interrupted by two introns of 78 and $53 \mathrm{bp}$ in length (Picart et al. 2012). Its $5^{\prime}$ untranslated region (cell $2 A_{\mathrm{p}}: 800 \mathrm{bp}$ ) was in silico analyzed (SnapGene Viewer) for the presence of DNA sequence motifs known to be recognized by relatively wellconserved Zn2Cys6 (i.e., CLR-1/ClrA, CLR-2/ClrB, Ace $2 / A c e B$, and X1nR/Xyr1/X1r-1) and Cys 2 His 2 (CreA/CRE1 and PacC/PAC1) transcription regulators of cellulase genes. As shown in Fig. 1, one (5'-YAGAAT-3'; at position -345 from the ATG-initiation codon) and three $\left(5^{\prime}\right.$ GGCWWW-3'; positions - 240, - 457, - 689) predicted DNA binding sequences for CLR-2 and XlnR, respectively (Benocci et al. 2017), were found in cell2A $A_{p}$, suggesting an in vivo positive role for these activators in the expression of
cel12A. Neither sites for CLR-1 nor for Ace2 were identified. The transcription activators CLR-2 and its ortholog ClrB are essential for cellulase gene expression in $N$. crassa and A. nidulans, respectively (Coradetti et al. 2012). Using the amino acid sequence of CLR-2/NCU08042 of $N$. crassa against the hypothetical proteome of $S$. atra (BLASTP), we found a highly homologous protein (KFA75600/ A0A084RHB5, >70\% identity) to CLR-2. Reciprocal BLASTP analysis confirmed that KFA75600 might be the cellulose regulator CLR-2 of $S$. atra. In addition, the Zn(II)2Cys6 DNA-binding domains of both CLR-2 orthologs are $100 \%$ identical suggesting that their DNA targets would also be conserved. On the other hand, the transcription activator XlnR regulates the expression of cellulase and hemicellulase genes in A. niger (van Peij et al. 1998; Stricker et al. 2008), whereas its ortholog (XLR-1) in $N$. crassa has a different role and predominantly regulates the expression of xylanolytic genes (Sun et al. 2012). BLASTP analysis using the amino acid sequence of the xylanolytic activator (XLR-1/NCU06971) of $N$. crassa revealed that $S$. atra also have an ortholog protein to XLR-1 (i.e., KFA73621/A0A084RBN6). The identity (100\%) in the $\mathrm{Zn}(\mathrm{II}) 2 \mathrm{Cys} 6$ regions of both XLR-1 orthologs suggests that they recognized identical DNA targets.

\footnotetext{
-800 ACCCGGATCGGCCCGAACCAGACTTCAGTACCCAA

-765 GGCCCCATAACCGAAACCTTCATTATAAGCGCGCTAATCAAGCGAGTGATGCTGACCCCTTGCT

-701 TCTATGCATTGCCATTTCAGTGCTATTGCGTACTCAACCAAAGTTTGGTTCGCTCCGATAGATA

-637 GATTAATGCTGAAGCAAAGGCCCGAAAACCCTTGTGCATGGCCTGAGGTCCACTTCCTAATGGG

-573 GATGCTGCTTAGACTTGCGATTCGTTGTGGCTGTAGATTGGTCCCCCCCGGGCCATGCAGTTAA

-509 TTTATAAATGATGAgCTATTAAGGTACAGCAAGCTCATAGAAACACATTGCCAAGGAAACACC

-445 ATGCAACAGGTGGAGAATCTTGGCTGCGATTAGCAAGTTGAGGGCAACCGCAGCTAGCCAAATA

-381 ACCAACCACCAAGTGATGGCCTTCAGTCGACCAAGACAGAATGCTCCGATGGAGTACTATAGTC

-317 ATTCATATGACACACCCAGTGTCATGCACCATTGTTTGTAACCGCTTACCTTTGGTCATGGGCC

-253 CCGAGTGCTAAGCCAACGAGATGTTGCATTCCCCTGGATGAACCCCTTTGGAAACGGACATAGT

-189 CAACCGAACATCTGGGGTCTGGGGTCAAGGCTCCGTTCAAACACAAGATGGCTTCGAGCTCTGA

-125 AgCTGCTATAAGTACATTGGGATCTATCTGGCGATCAGACGAACAGAGCCAGATGAAGCAACTT

-61 GCCAGAACAGTATCTTCAATTGATCATCGTCAACAAGGTTCAAGCCTGCTAGCTGTCAAACATG
}

Fig. 1 DNA sequence of the cell2A gene promoter of $S$. atra BP-A. Putative TATA box and the translational initiation codon are shown in bold. The four DNA sequences (two 5'-CTGGGG-3', one 5'-GTGGAG$3^{\prime}$ and one $5^{\prime}$-CCGGGG- $3^{\prime}$ ) conforming the consensus binding site for CreA (5'-SYGGRG-3') are shown in bold and underlined whereas those for PacC (two 5'-GCCAAG-3') are shown double underlined. The putative DNA binding site ( $5^{\prime}$-CAGAAT- $\left.3^{\prime}\right)$ for CLR-2 is underlined, whereas those for XlnR (one $5^{\prime}$-GGCTTA-3' and two 5'-GGCAAT-3') are shadowed in gray. Although these sequences are located on both strands, only the top strand is indicated 
Four DNA sequences matching the hexanucleotide 5'SYGGRG-3' described as the binding site for the widedomain glucose repressor CreA (Kulmburg et al. 1993; Cubero and Scazzocchio 1994) were also found in cel12A (Fig. 1). Two of these sequences are located at positions -523 and -436 from the ATG codon, whereas the other two are adjacent and directly oriented sequences separated by one base pair (5'-CTGGGGnCTGGGG-3'; positions - 178 and -171 from the ATG), strongly suggesting that the expression of cell $2 \mathrm{~A}$ is subjected to CCR directly mediated by CreA. It is in this regard noteworthy that a physiological role for CreA sites conforming the sequence $5^{\prime}$-CTGGGG-3' has been shown in both the intergenic region between $\operatorname{prn} D$ and $\operatorname{prn} B$ (Cubero and Scazzocchio 1994) and the promoter region of the xylanase gene $x \ln A$ (Orejas et al. 1999) of A. nidulans. BLASTP and reciprocal BLASTP analyses revealed that S. atra also has one hypothetical protein (KFA75113/ A0A084RFX8) ortholog to the CreA repressor (AN6195) of A. nidulans.

Finally, two copies of the DNA consensus sequence 5'GCCARG-3', which is the binding site of the main regulatory protein $(\mathrm{PacC})$ controlling $\mathrm{pH}$-dependent transcriptional regulation in A. nidulans (Caddick et al. 1986; Tilburn et al. 1995) and other fungi, were detected in cell $2 A_{\mathrm{p}}$ at positions -422 and -459 from the ATG (Fig. 1). This observation suggests that expression of cell2A could be also controlled by the $\mathrm{pH} / \mathrm{PacC}$ regulatory circuit. Using the BLASTP program, PacC (AN2855) has been also shown to have one putative ortholog in S. atra (KFA79600/A0A084RTR5).

In summary, in silico analysis of the $5^{\prime}$ flanking region adjacent to cell $2 \mathrm{~A}$ resulted in the identification of motifs and promoter elements that could be involved in its regulation. BLAST searches against the proteome of $S$. atra resulted in the identification of hypothetical regulatory proteins that could bind to those promoter targets to modulate the expression of cel12A. Rational engineering of these transcriptional factors could allow to enhance the production of not only Cel12A but also other industrially important PCWDE in $S$. atra or other Stachybotrys species (according to the JGI Genome Portal MycoCosm, the genome of S. elegans MPICAGE-CH-0235 has potential to encode 841 carbohydrate acting enzymes, while that of the industrial enzyme producers A. niger and T. reesei would encode 516 and 407, respectively). A similar strategy has been successfully applied to enhance the production of endogenous and heterologous PCWDEs in A. nidulans (Tamayo-Ramos and Orejas 2014). Moreover, as a biocontrol activity has been suggested for some Stachybotrys species, and expression of genes encoding extracellular enzymes associated with mycoparasitism (proteases, $\beta$-glucanases, chitinases, and other fungal cell walldegrading enzymes) could be also controlled by the carbon source and ambient $\mathrm{pH}$, the identification of the potential regulatory proteins KFA79600/PacC and KFA75113/CreA of
Stachybotrys could provide a better knowledge of the molecular mechanism involved in its mycoparasitism and thus help to improve its biocontrol efficiency against fungal pathogens.

\section{Influence of carbon sources and ambient pH on lichenase production}

The potential regulatory elements found in the promoter of cel1 $2 \mathrm{~A}$ as well as the activity of its gene product suggested that expression of $c e l 12 \mathrm{~A}$ could be at least regulated by two abiotic factors: carbon source (induced by cellulosic/ hemicellulosic substrates and repressed by glucose) and ambient $\mathrm{pH}$. Regarding to the inducing carbon source, current research into PCWDEs focuses on their uses in the bioconversion of agricultural wastes, as well as the environmental benefits that could have the use of these substrates. It has been reported that rice straw (one of the abundant lignocellulosic waste materials in the world; Karimi et al. 2006) greatly induced the production of cellulases in S. atra BP-A (Picart et al. 2008 ) and $\beta$-glucanases in Aspergillus terreus ASKU 10 (Prajanban et al. 2008). On the other hand, in the CCR/CreA system of $A$. nidulans, lactose is considered to be a nonrepressing carbon source, whereas $0.1 \%$ glucose is less repressing than $1 \%$ glucose (Bailey and Arst 1975).

Previous studies in our group of research (unpublished results) showed the presence of at least three protein bands in SDS-PAGE which zymography revealed to have lichenase activity under rice straw conditions. Bearing this study in mind along with the abovementioned considerations, to assess whether lichenase biosynthesis in S. atra is indeed regulated by the carbon source, extracellular lichenase activity was firstly compared in transfer experiments from $1 \%$ glucose to potential inducing ( $1 \%$ rice straw), non-repressing ( $1 \%$ lactose), and two different levels of repressing conditions (1\% glucose and $0.1 \%$ glucose). As seen in Fig. 2, the complex source of carbon rice straw (predominantly contains cellulose (3047\%), hemicellulose (19-27\%), and lignin; Karimi and Taherzadeh 2016; Jin and Chen 2007; Horikawa et al. 2011) was the most effective inducer among the carbon sources tested. In the sole presence of this substrate, extracellular lichenase activity was 6-fold greater than that obtained in $0.1 \%$ glucose $(0.36$ vs $0.06 \mathrm{U} / \mathrm{mL})$, while it was not detected in $1 \%$ lactose or $1 \%$ glucose. These results suggest that in $S$. atra, lichenase activity is produced at a basal level which is induced by rice straw and repressed by glucose and lactose.

To assess whether glucose also represses lichenase induction, extracellular lichenase activity was studied in transfer experiments to rice straw media with and without glucose. Figure 2 shows that lichenase activity was abolished when $1 \%$ glucose was combined with the inducer indicating that the induction of lichenase in $S$. atra is under CCR. As expected, lichenase activity was about $50 \%$ lower in media cosupplemented with rice straw and $0.1 \%$ glucose $(0.19 \mathrm{U} /$ 
Fig. 2 Influence of the carbon source and ambient $\mathrm{pH}$ on $\mathrm{S}$. atra BP-A lichenase production. Rice straw at $1 \%$ and rice straw at $1 \%$ buffered at two different initial $\mathrm{pH}$ conditions (acidic 5.2, and alkaline 7.9), glucose at $1 \%$ and $0.1 \%$, and lactose at $1 \%$, used individually and combined with RS at $1 \%$. Bars represent the lichenase activity (mean \pm standard deviation), whereas the line shows the total extracellular protein concentration (mean \pm standard deviation) (RS,

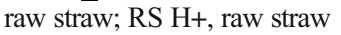
adjusted at acidic $\mathrm{pH}$ 5.2; $\mathrm{RS} \mathrm{OH}-$, raw straw adjusted at alkaline $\mathrm{pH}$ 7.9; G1, $1 \%$ glucose; G0.1, $0.1 \%$ glucose; and L1, $1 \%$ lactose)

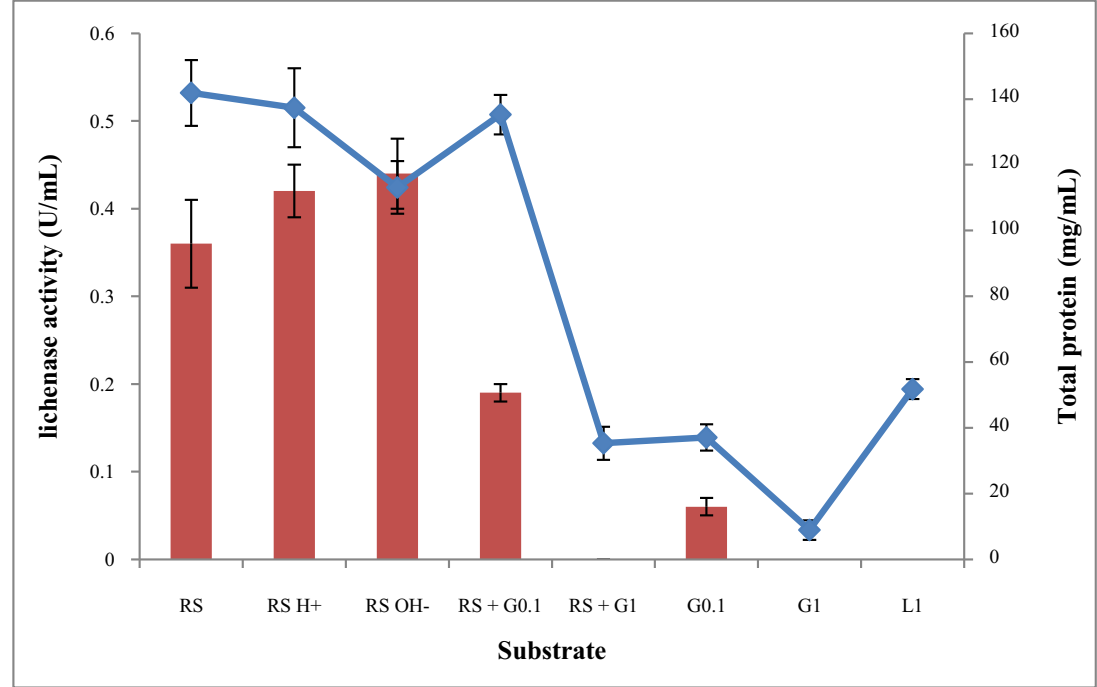

$\mathrm{mL}$ ) than in the sole presence of rice straw, indicating that induction is partially repressed under low concentration of the repressor (glucose). Not surprisingly, the amount of secreted proteins varied depending on the nature of the carbon source (Fig. 2). In the presence of complex substrates such as rice straw, more enzymes (lichenase and other PCWDEs) should be induced than in its absence or in the presence of repressing conditions ( $1 \%$ glucose) where biosynthesis of most of these enzymes is negatively affected.

It can therefore be concluded that lichenase activity (including Cel12A) in S. atra is induced by rice straw and this induction repressed by glucose. In a previous study, we have also found that $S$. atra BP-A secreted high cellulase activity when grown on rice straw, and this is not produced in the presence of glucose (Picart et al. 2008), suggesting that lichenase and cellulase genes might be co-regulated, and their promoters would share common cis-acting elements. The production profile of lichenase activity in S. atra is also similar to that of the Stachybotrys microspore endoglucanase, which is highly produced on cellulosic substrates such as wheat bran, and repressed on lactose and glucose (Ben Hmad et al. 2014), and to that of $P$. occitanis lichenase, where its production is greatly induced by cellulose, barley flour, barley bran, and oat flour (Chaari et al. 2014).

Finally, to investigate the effect of ambient $\mathrm{pH}$ on lichenase production, lichenase activity was studied in transfer experiments to inducing media (1\% rice straw) buffered at acidic $(\mathrm{pH}$ 5.2) or alkaline (pH 7.9) $\mathrm{pH}$ values. As seen in Fig. 2, both $\mathrm{pH}$ conditions gave similar yields of extracellular lichenase activity (about $0.4 \mathrm{U} / \mathrm{mL}$ ), suggesting the lack of a role for $\mathrm{pH}$ and $\mathrm{PacC}$ in the synthesis of lichenase. Similar yields were also reached in the presence of phosphate $(0.36 \mathrm{U} /$ $\mathrm{mL}$ ) indicating the lack of a role for this supplement. Interestingly, most of cellulolytic fungi show an acidic $\mathrm{pH}$ optimum for PCWDEs secretion (Chaari et al. 2014;
Elgharbi et al. 2013; Grishutin et al. 2006; Murray et al. 2001). Instead, S. atra BP-A produced Cel12A at both acidic and alkaline $\mathrm{pH}$, a behavior that seems not to be very often among fungi.

\section{Analysis of cel12A expression in response to carbon source and ambient pH}

To investigate whether the results obtained at the lichenase activity level correlated with differences in the expression of cell $2 A$, its steady-state mRNA levels were quantified (by RTqPCR) in mycelia obtained from the same cultures used to measure lichenase activity. The housekeeping gene $18 \mathrm{~S}$ $r R N A$ was firstly validated to normalize cel12A expression data. As shown in Table 2, $18 \mathrm{~S}$ rRNA displayed similar $\mathrm{C}_{\mathrm{t}}$ values across all experimental samples, indicating that its expression is stable in these conditions and it can therefore be considered a suitable reference gene. We have validated the $18 S$ rRNA as a reference gene for RT-qPCR analysis in $S$. atra, and we expect that it could potentially be used to normalize other results of gene expression in this fungus.

In contrast to the stable expression of $18 S r R N A$, the $\mathrm{C}_{\mathrm{t}}$ values of cell $2 \mathrm{~A}$ varied widely among the different growth conditions analyzed (Table 2), indicating that its expression is regulated. We arbitrary assigned as a reference sample the $\mathrm{C}_{\mathrm{t}}$ value derived from the cultures of $S$. atra BP-A in $1 \%$ rice straw as a sole carbon source (considered to be an inducing condition for lichenase activity, see above). To assess whether rice straw also induced gene expression of lichenase genes, Cel12A transcripts from mycelia grown either in $1 \%$ rice straw, $1 \%$ lactose, or $0.1 \%$ glucose were quantified. Table 2 shows that the relative mRNA levels of cel12A are elevated in rice straw in comparison to those in the sole presence of $1 \%$ lactose (about 11 -fold) or $0.1 \%$ glucose (about 58 -fold), indicating that transcription of $c e l 12 \mathrm{~A}$ is indeed activated by rice 
Table 2 Relative expression of cell2A and $18 S$ rRNA in S. atra BP-A

\begin{tabular}{|c|c|c|c|c|c|}
\hline Sample & Mean $\mathrm{C}_{\mathrm{tCel} 12 \mathrm{~A}}$ & Mean $\mathrm{C}_{\mathrm{tRNA} 18 \mathrm{~s}}$ & $\Delta \mathrm{Ct}\left(\mathrm{C}_{\mathrm{tCel} 12 \mathrm{~A}}-\mathrm{C}_{\mathrm{t} 18 S r R N A}\right)$ & $\Delta \Delta \mathrm{C}_{\mathrm{t}}$ & $2^{-\Delta \Delta \mathrm{Ct}}(-$ fold $)$ \\
\hline $1 \%$ Rice straw & $29.35 \pm 0.305$ & $15.537 \pm 0.015$ & $14.108 \pm 0.124$ & $0.0 \pm 0.124$ & $1.0 \pm 0.124$ \\
\hline 1\% Rice straw pH 5.2 & $28.413 \pm 0.244$ & $15.85 \pm 0.111$ & $12.563 \pm 0.268$ & $-1.545 \pm 0.268$ & $2.918 \pm 0.596$ \\
\hline 1\% Rice straw pH 7.9 & $28.576 \pm 0.069$ & $16.163 \pm 0.051$ & $12.412 \pm 0.086$ & $-1.696 \pm 0.087$ & $3.24 \pm 0.195$ \\
\hline $1 \% \mathrm{R}$ straw $+0.1 \%$ glucose & $33.71 \pm 0.325$ & $15.503 \pm 0.075$ & $18.207 \pm 0.334$ & $4.099 \pm 0.334$ & $-17.136 \pm 3.546$ \\
\hline $1 \% \mathrm{R}$ straw $+1 \%$ glucose & $\mathbf{3 8 . 9 8} \pm 0.352$ & $14.94 \pm 0.026$ & & & \\
\hline $0.1 \%$ Glucose & $35.123 \pm 0.201$ & $15.16 \pm 0.026$ & $19.963 \pm 0.203$ & $5.855 \pm 0.203$ & $-57.88 \pm 8.745$ \\
\hline $1 \%$ Glucose & $\mathbf{3 8 . 9 7 3} \pm 0.140$ & $15.547 \pm 0.032$ & & & \\
\hline $1 \%$ Lactose & $32.637 \pm 0.238$ & $15.10 \pm 0.040$ & $17.537 \pm 0.33$ & $3.429 \pm 0.33$ & $-10.77 \pm 2.769$ \\
\hline Distilled water & $\mathbf{3 9 . 1 9} \pm 0.26$ & $38.647 \pm 0.608$ & & & \\
\hline
\end{tabular}

Values are expressed as the means with their standard deviation. The expression level of cel $12 \mathrm{~A}$ in $1 \%$ rice straw was arbitrarily assigned as the reference sample with a $2^{-\Delta \Delta \mathrm{Ct}}$ value of 1.0. $\mathrm{C}_{\mathrm{tCel1}} \mathrm{A}$ values in bold correspond to values found for water and thus represent no expression of $\mathrm{cel} 12 \mathrm{~A}$

straw. Likewise, cell $2 A$ mRNAs accumulated upon transfer to $1 \%$ rice straw but not (the $\mathrm{C}_{\mathrm{t}}$ values are almost identical to those of the water control, about 39) in mycelia transferred to $1 \%$ rice straw $+1 \%$ glucose, or to $1 \%$ glucose alone (the pregrowth condition), clearly indicating that $1 \%$ glucose totally represses the expression of $c e l 12 A$ (with or without the inducer). Repression of the induction of cell2A is less pronounced at low glucose concentrations, as reflected by the amount of cel12A transcripts that was reduced 17-fold when the mycelia were grown in rice straw $+0.1 \%$ glucose relative to growths in $1 \%$ rice straw (Table 2). Great repression by $0.1 \%$ glucose of cel12A was observed in the absence of the inducer (about 58fold less mRNA in $0.1 \%$ glucose than in $1 \%$ rice straw, and a high $C_{t}$ value $>35$ ). Qualitatively, these results are in good agreement with those of lichenase activity (Fig. 2). The exception is the response of $S$. atra to $1 \%$ lactose. While this carbon source allows a certain expression of cel12A, extracellular lichenase activity was undetectable. One possible explanation to this result is a possible degradation of Cel12A by protease(s) produced in the presence of lactose. Protease production in fungi under specific growth conditions has already been reported (de Souza et al. 2015). Similar to cel12A, moderate expression of some $T$. reesei cellulolytic genes in the presence of lactose has also been reported (Amore et al. 2013 and references therein).

Transcription of cel12A was also analyzed in mycelia grown in $1 \%$ rice straw under acidic $(\mathrm{pH} 5.2)$ and alkaline (pH 7.9) conditions. In agreement to the lichenase activity data (Fig. 2), transcript levels of cel12A were very similar under both $\mathrm{pH}$ conditions (Table 2), indicating that transcription of cell $2 \mathrm{~A}$ is independent of the $\mathrm{pH} / \mathrm{PacC}$ regulatory circuit as well as the lack of a physiological role for the three consensus PacC target sites in cel12 $A_{\mathrm{p}}$. It is interesting that acid or alkaline $\mathrm{pH}$ conditions are not affecting - as it seems in Fig. 2 - the total extracellular lichenase activity, whereas the mRNA of cel12A (Table 2) accumulated at greater levels in buffered media than under control. It can be speculated that other lichenase activities could be masking the expression profile of cel12A.

Taken together these results demonstrate that both rice straw induction and glucose repression (CCR) of lichenase production in $S$. atra take place at the level of transcription of at least cel12A. The presence of potential target sequences for the cellulase/hemicellulase transcription activators CLR-2 and $\mathrm{X} \operatorname{lnR}$ in cell2 $A_{\mathrm{p}}$ suggests a positive role for their orthologs (KFA75600 and KFA73621, respectively) activating cell $2 \mathrm{~A}$ transcription in the presence of raw straw. Likewise, the presence of four CreA consensus binding sites in cel1 $2 A_{\mathrm{p}}$ would suggest direct repression of cel12A by $\mathrm{CreA} / \mathrm{KFA} 75113$ in the presence of glucose with and without rice straw. With regard to the molecular mechanism by which CreA/KFA75113 would repress cel12A transcription, the fact that the potential CLR-2, XlnR, and CreA targets do not overlap would rule out direct competition between CreA and the potential transcription activators.

\section{Conclusions}

In this study, we report on the expression of a gene encoding an extracellular lichenase activity in the genus Stachybotrys. From 2015, the genome sequence of $S$. chartarum (AKA S. atra) is publicly available (Betancourt et al. 2015). Its in silico analyses resulted in the identification of transcriptional factors orthologs to PacC, CreA, CLR-2, and XlnR, which regulate the expression of PCWDEs in several filamentous fungi. Further manipulation of these control systems (e.g., rational engineering of $\mathrm{CreA}$ to remove $\mathrm{CCR}$ ) may significantly improve yields of Cel12A and another PCWDEs in S. atra. Taking into account the key role of lichenases in biotechnological applications (e.g., brewing, animal foodstuffs) as well as the fact that these enzymes are an essential component of the enzyme portfolio for degrading the lignocellulose resources to produce biofuel (Dashtban et al. 2010), 
it is evident that new knowledge about the biochemical properties of these enzymes and the regulatory mechanisms involved in their production in various microorganisms is still necessary. Consequently, we believe that the present work will set the basis for further research on the genus Stachybotrys and will encourage other scientists to study the transcriptional regulation and recombinant production of new PCWDEs produced by these important cellulolytic fungi. In addition, open-field burning of rice residues has harmful environmental implications, and thus the use of this substrate to generate value-added products such as ethanol or enzymes could help to alleviate problems related to their disposal. In this regard, since promoters are key tools in biotechnology to ensure that gene expression is effective, rice straw responding promoters (such as cell $2_{\mathrm{p}}$ ) for the overexpression of transgenes could well be an interesting alternative to valorize this agriculture by-product.

Funding This work was supported by research grants AGL2015-66131C2-2-R (CICYT-FEDER), CTQ2017-84966-C2-2-R, and PROMETEO/ 2018/066 (Generalitat Valenciana).

\section{Compliance with ethical standards}

Conflict of interest The authors declare that they have no conflict of interest.

\section{References}

Abdeljalil S, Trigui-Lahiani H, Lazzez H, Gargouri A (2013) Cloning, molecular characterization, and mRNA expression of the thermostable family $3 \beta$-glucosidase from the rare fungus Stachybotrys microspora. Mol Biotechnol 54:842-852

Abdeljalil S, Ben Hmad I, Saibi W, Amouri B, Maalej W, Kaaniche M, Koubaa A, Gargouri A (2014) Investigations on hydrolytic activities from hydrolytic activities from Stachybotrys microspora and their use as an alternative in yeast DNA extraction. Appl Biochem Biotechnol 172:1599-1611

Abdel-Mallek AY (1994) Isolation of cellulose-decomposing fungi from damaged manuscripts and documents. Microbiol Res 149:163-165

Adnan M, Zheng W, Islam W, Arif M, Abubakar YS, Wang Z, Lu G (2018) Carbon catabolite repression in filamentous fungi. Int J Mol Sci 19:48

Altschul SF, Madden TL, Schäffer AA, Zhang J, Zhang Z, Miller W, Lipman DJ (1997) Gapped BLAST and PSI-BLAST: a new generation of protein database search programs. Nucleic Acids Res 25(17):3389-3402

Amore A, Giacobbe S, Faraco V (2013) Regulation of cellulase and hemicellulase gene expression in fungi. Curr Genomics 14:230-249

Aro N, Pakula T, Penttila M (2005) Transcriptional regulation of plant cell wall degradation by filamentous fungi. FEMS Microbiol Rev 29:719-739

Bailey C, Arst Jr HN (1975) Carbon catabolite repression in Aspergillos nidulans. Eur J Biochem 51(2):573-577

Ben Hmad I, Abdeljalil S, Saibi W, Amouri B, Gargouri A (2014) Medium initial $\mathrm{pH}$ and carbon source stimulate differential alkaline cellulase time course production in Stachybotrys microspora. Appl Biochem Biotechnol 172:2640-2649
Benocci T, Aguilar-Pontes MV, Zhou M, Seiboth B, de Vries RP (2017) Regulators of plant biomass degradation in ascomycetous fungi. Biotechnol Biofuels 10:152

Betancourt DA, Dean TR, Kim J, Levy J (2015) Genome sequence of Stachybotrys chartarum strain 51-11. Genome Announc 3:14-15

Bradford MM (1976) A rapid and sensitive method for the quantitation of microgram quantities of protein utilizing the principle of protein-dye binding. Anal Biochem 72:248-254

Brasel TL, Douglas DR, Wilson SC, Straus DC (2005) Detection of airborne Stachybotrys chartarum macrocyclic trichothecene mycotoxins on particulates smaller than conidia. Appl Environ Microbiol $71: 114-122$

Caddick MX, Brownlee AG, Arst HN Jr (1986) Regulation of gene expression by $\mathrm{pH}$ of the growth medium in Aspergillus nidulans. Mol Gen Genet 203:346-353

Chaari F, Ellouz Chaabouni S (2019) Fungal beta-1,3-1,4-glucanases: production, proprieties and biotechnological applications. J Sci Food Agric 99:2657-2664

Chaari F, Belghith-Fendri L, Blibech M, Driss D, Ellouzi SZ, Sameh M, Ellouz Chaabouni S (2014) Biochemical characterization of a lichenase from Penicillium occitanis Pol6 and its potential application in the brewing industry. Process Biochem 49:1040-1046

Chamoun R, Aliferis KA, Jabaji S (2015) Identification of signatory secondary metabolites during mycoparasitism of Rhizoctonia solani by Stachybotrys elegans. Front Microbiol 6:353

Coradetti ST, Craig JP, Xiong Y, Shock T, Tian C, Glass NL (2012) Conserved and essential transcription factors for cellulase gene expression in ascomycete fungi. Proc Natl Acad Sci 109:7397-7402

Cubero B, Scazzocchio C (1994) Two different, adjacent and divergent zinc finger binding sites are necessary for CREA-mediated carbon catabolite repression in the proline gene cluster of Aspergillus nidulans. EMBO J 13:407-415

Dashtban M, Schraft H, Qin W (2010) Fungal bioconversion of lignocellulosic residues; opportunities \& perspectives. Int J Biol Sci 5:578595

de Souza PM, Bittencourt ML, Caprara CC, de Freitas M, de Almeida RP, Silveira D, Fonseca YM, Ferreira Filho EX, Pessoa Junior A, Magalhães PO (2015) A biotechnology perspective of fungal proteases. Braz J Microbiol 46:337-346

Elgharbi F, Hmida-Sayari A, Sahnoun M, Kammoun R, Jlaeil L, Hassairi $\mathrm{H}$, Bejar S (2013) Purification and biochemical characterization of a novel thermostable lichenase from Aspergillus niger US368. Carbohydr Polym 98:967-975

Etzel RA, Montana E, Sorenson WG et al (1998) Acute pulmonary hemorrhage in infants associated with exposure to Stachybotrys atra and other fungi. Arch Pediatr Adolesc Med 152:757-762

Goldenkova-Pavlova IV, Tyurin AA, Mustafaev ON (2018) The features that distinguish lichenases from other polysaccharide-hydrolyzing enzymes and the relevance of lichenases for biotechnological applications. Appl Microbiol Biotechnol 102:3951-3965

Grishutin SG, Gusakov AV, Dzedzyulya EI, Sinitsyn AP (2006) A lichenase-like family 12 endo-(1->4)-beta-glucanase from Aspergillus japonicus: study of the substrate specificity and mode of action on beta-glucans in comparison with other glycoside hydrolases. Carbohydr Res 341:218-229

Horikawa Y, Imai T, Takada R, Watanabe T, Takabe K, Kobayashi Y, Sugiyama J (2011) Near-infrared chemometric approach to exhaustive analysis of rice straw pretreated for bioethanol conversion. Appl Biochem Biotechnol 164:194-203

Huberman LB, Liu J, Qin L, Glass NL (2016) Regulation of the lignocellulolytic response in filamentous fungi. Fungal Biol Rev 30:101-111

Jin S, Chen H (2007) Near-infrared analysis of the chemical composition of rice straw. Ind Crop Prod 26:207-211 
Karimi K, Taherzadeh MJ (2016) A critical review of analytical methods in pretreatment of lignocelluloses: Composition, imaging, and crystallinity. Bioresour Technol 200:1008-1018

Karimi K, Kheradmandinia S, Taherzadeh MJ (2006) Conversion of rice straw to sugars by dilute-acid hydrolysis. Biomass Bioenergy 30 : 247-253

Kulmburg P, Mathieu M, Dowzer C, Kelly J, Felenbok B (1993) Specific binding sites in the alcR and alcA promoters of the ethanol regulon for the CREA suppressor mediating carbon catabolite repression in Aspergillus nidulans. Mol Microbiol 7:847-857

MacCabe AP, Orejas M, Pérez-González JA, Ramón D (1998) Opposite patterns of expression of two Aspergillus nidulans xylanase genes with respect to ambient $\mathrm{pH}$. J Bacteriol 180:1331-1333

MacCabe, Orejas M, Tamayo EN, Villanueva A, Ramón D (2002) Improving extracellular production of food-use enzymes from Aspergillus nidulans. J Biotechnol 96:43-54

Mandels M, Weber J (1969) The production of cellulases. Adv Chem 95: $391-413$

Martin K, McDougall BM, McIlroy S, Chen J, Seviour RJ (2007) Biochemistry and molecular biology of exocellular fungal beta-(1, 3)- and beta-(1,6)-glucanases. FEMS Microbiol Rev 31:168-192

Morissette DC, Driscoll BT, Jabaji-Hare S (2003) Molecular cloning, characterization, and expression of a cDNA encoding an endochitinase gene from the mycoparasite Stachybotrys elegans. Fungal Genet Biol 39:276-285

Morissette DC, Seguin P, Jabaji-Hare SH (2006) Expression regulation of the endochitinase-encoding gene sechi44 from the mycoparasite Stachybotrys elegans. Can J Microbiol 52:1103-1109

Morissette DC, Dauch A, Beech R, Masson L, Brousseau R, Jabaji-Hare S (2008) Isolation of mycoparasitic-related transcripts by SSH during interaction of the mycoparasite Stachybotrys elegans with its host Rhizoctonia solani. Curr Genet 53:67-80

Morse DL, Carroll D, Weberg L, Borgstrom MC, Ranger-Moore J, Gillies RJ (2005) Determining suitable internal standards for mRNA quantification of increasing cancer progression in human breast cells by real-time reverse transcriptase polymerase chain reaction. Anal Biochem 342:69-77

Murray PG, Grassick A, Laffey CD, Cuffe MM, Higgins T, Savage AV, Planas A, Tuohy MG (2001) Isolation and characterization of a thermostable endo- $\beta$-glucanase active on 1,3-1,4- $\beta$-D-glucans from the aerobic fungus Talaromyces emersonii CBS 814.70. Enzym Microb Technol 29:90-98

Orejas M, Espeso EA, Tilburn J, Sarkar S, Arst HN Jr, Penalva MA (1995) Activation of the Aspergillus PacC transcription factor in response to alkaline ambient $\mathrm{pH}$ requires proteolysis of the carboxy-terminal moiety. Genes Dev 9:1622-1632

Orejas M, MacCabe AP, Pérez González JA, Kumar S, Ramón D (1999) Carbon catabolite repression of the Aspergillus nidulans $x \ln A$ gene. Mol Microbiol 31:177-184

Peñalva MA, Arst HN Jr (2004) Recent advances in the characterization of ambient $\mathrm{pH}$ regulation of gene expression in filamentous fungi and yeasts. Annu Rev Microbiol 58:425-451

Peñalva MA, Tilburn J, Bignell E, Arst HN Jr (2008) Ambient pH gene regulation in fungi: making connections. Trends Microbiol 16:291300
Picart P, Diaz P, Pastor FI (2008) Stachybotrys atra BP-A produces alkali-resistant and thermostable cellulases. Antonie Van Leeuwenhoek 94:307-316

Picart P, Goedegebuur F, Diaz P, Pastor FI (2012) Expression of a novel beta glucanase from Stachybotrys atra in bacterial and fungal hosts. Fungal Biol 116:443-451

Picart P, Orejas M, Pastor FI (2016) Recombinant expression of a GH12 $\beta$-glucanase carrying its own signal peptide from Stachybotrys atra in yeast and filamentous fungi. World J Microbiol Biotechnol 32: $123-127$

Prajanban J, Thongkhib C, Kitpreechavanich V (2008) Selection of high $\beta$-glucanase produced Aspergillus strain and factors affecting the enzyme production in solid-state fermentation. Kasetsart $J$ (Nat Sci) 42:294-299

Saibi W, Amouri B, Gargouri A (2007) Purification and biochemical characterization of a transglucosilating beta-glucosidase of Stachybotrys strain. Appl Microbiol Biotechnol 77:293-300

Spiro RG (1966) The Nelson-Somogyi copper reduction method. Analysis of sugars found in glycoprotein. Methods Enzymol 8:3-26

Stricker AR, Mach RL, de Graaff LH (2008) Regulation of transcription of cellulases- and hemicellulases-encoding genes in Aspergillus niger and Hypocrea jecorina (Trichoderma reesei). Appl Microbiol Biotechnol 78:211-220

Sun J, Tian C, Diamond S, Glass NL (2012) Deciphering transcriptional regulatory mechanisms associated with hemicellulose degradation in Neurospora crassa. Eukaryot Cell 11:482-493

Tamayo-Ramos JA, Orejas M (2014) Enhanced glycosyl hydrolase production in Aspergillus nidulans using transcription factor engineering approaches. Biotechnol Biofuels 7:103

Taylor G, Suha J, Pierre M, Wagahatullam K (2002) Purification and characterization of an extracellular exochitinase, BNacetylhexosaminidase, from the fungal mycoparasite Stachybotrys elegans. Can J Microbiol 48:311-319

Thomas R (1956) Fungal cellulases: Stachybotrys atra: production and properties of the cellulolytic enzyme. Aust J Biol Sci 9:159-183

Tilburn J, Sarkar S, Widdick DA, Espeso EA, Orejas M, Mungroo J, Peñalva MA, Arst HN Jr (1995) The Aspergillus PacC zinc finger transcription factor mediates regulation of both acid- and alkalineexpressed genes by ambient $\mathrm{pH}$. EMBO J 14:779-790

Tweddell RJ, Marchall J, Jabaji-Hare SH (1996) Endo-1,3 beta-glucanase production by Stachybotrys elegans, a mycoparasite of Rhizoctonia solani. Mycologia 88:410-415

van Peij NN, Gielkens MM, de Vries RP, Visser J, de Graaff LH (1998) The transcriptional activator XlnR regulates both xylanolytic and endoglucanase gene expression in Aspergillus niger. Appl Environ Microbiol 64:3615-3619

Wang Y, Hyde KD, McKenzie EHC, Jiang YL, Li DW, Zhao DG (2015) Overview of Stachybotrys (Memnoniella) and current species status. Fungal Divers 71:17-83

Publisher's note Springer Nature remains neutral with regard to jurisdictional claims in published maps and institutional affiliations. 